\title{
Short communication: Circulating serotonin (5-HT) concentrations on day 1 of lactation as a potential predictor of transition-related disorders
}

\author{
J. Laporta, S. A. E. Moore, M. W. Peters, T. L. Peters, and L. L. Hernandez ${ }^{1}$ \\ Department of Dairy Science, University of Wisconsin, Madison 53706
}

\begin{abstract}
The monoamine serotonin (5-hydroxytryptamine; 5 -HT) has been described as a homeostatic regulator of lactation. Recently, our laboratory determined that 5 -HT is involved in the regulation of calcium and glucose homeostasis during the transition period in rodents. More specifically, we demonstrate that 5 - $\mathrm{HT}$ is responsible for calcium mobilization from bone and upregulation of hepatic gluconeogenic enzymes and mammary gland glucose transporters. Our objective was to investigate the correlation between circulating 5-HT concentrations and circulating ionized calcium, parathyroid hormone-related protein (PTHrP), and glucose concentrations on d 1 postpartum. We also investigated the correlation between circulating 5 -HT and milk fever and ketosis incidence and severity in multiparous Holstein cows at the onset of lactation. Blood samples were collected from 42 multiparous cows on d 1 of lactation and analyzed for 5-HT, calcium, glucose, and PTHrP. Milk fever (determined subjectively for each cow on $\mathrm{d}$ 1 postpartum) and ketosis incidence and severity (scale 1 to 4 , determined objectively for each cow during the first $10 \mathrm{~d}$ postpartum) were recorded for all animals. Serum 5-HT was positively correlated with serum calcium and with plasma PTHrP ( $r>0.37)$. Serum 5-HT was negatively correlated with milk fever incidence and with ketosis severity (most severe ketosis incidence recorded during the first $10 \mathrm{~d}$ postpartum; $\mathrm{r}<-0.33$ ). Serum calcium and plasma glucose concentrations were negatively correlated with milk fever and ketosis severity, respectively $(\mathrm{r}<-0.39)$. These data indicate that 5-HT potentially plays a role in the regulation of calcium and glucose homeostasis during the transition period in cattle, which we previously demonstrated in rodents. Increased circulating concentrations of 5-HT might decrease milk fever at the onset of lactation and ketosis severity during the first $10 \mathrm{~d}$ postpartum in dairy cows. Understanding this physiological axis could help describe the underlying mechanisms associated
\end{abstract}

Received February 21, 2013.

Accepted April 24, 2013.

${ }^{1}$ Corresponding author: llhernandez@wisc.edu with these periparturient metabolic disorders in dairy cows.

Key words: serotonin, calcium, ketosis, milk fever

\section{Short Communication}

The transition period ( $3 \mathrm{wk}$ prepartum through $3 \mathrm{wk}$ postpartum) is an extremely critical period in the life of a dairy cow. Most high-producing dairy cows in early lactation go through a period of negative energy balance, due to a metabolic necessity for milk production (Grummer, 1995). Particularly, the rising demands for calcium and glucose by the mammary gland place extreme pressures on their homeostatic regulatory mechanisms during this period. At this time, cows are highly susceptible to a variety of periparturient diseases, such as milk fever and ketosis, that negatively affect health, their overall production, and the subsequent reproductive cycle resulting in substantial economic losses for dairy farmers (Erb et al., 1985).

Serotonin (5-hydroxytryptamine; $\mathbf{5 - H T}$ ) is an established homeostatic regulator of the mammary gland (Collier et al., 2012), and has recently been demonstrated to significantly affect calcium and glucose homeostasis during the transition period in mice and rats (Hernandez et al., 2012; Laporta et al., 2013a,b). Specifically, our laboratory demonstrated that 5-HT is responsible for bone calcium mobilization and hepatic upregulation of gluconeogenic enzymes as well as mammary gland glucose transporters, and that 5-HT can affect mammary gland energy metabolism during the transition period in a rat model (Laporta et al., 2013a,b). Previous studies have also indicated that 5 -HT is a regulator of glucose metabolism (Watanabe et al., 2011). Furthermore, 5-HT has recently been determined to increase production of parathyroid hormone-related protein (PTHrP) in the mammary gland during lactation, which is critical for initiating calcium mobilization from bone to support milk formation (Wysolmerski, 2010; Kovacs, 2011; Hernandez et al., 2012).

To date, the role of 5-HT in the regulation of calcium and glucose homeostasis in dairy cattle remains largely unknown. Thus, the objectives of this study were to 
determine if circulating 5 -HT concentrations on $\mathrm{d} 1$ postpartum were correlated with circulating ionized calcium, PTHrP, and glucose concentrations, as well as to assess the relationship between circulating 5-HT and the incidence of milk fever (postpartum d 1, onset of lactation) and incidence and severity (during the first $10 \mathrm{~d}$ postpartum) of ketosis in Holstein dairy cows.

All experiments were performed under protocols approved by the Animal Care and Use Committee at the University of Wisconsin-Madison. Forty-two multiparous Holstein cows (BCS optimized to $3.7 \pm 0.5$ at freshening, average lactation number $=3.4$ ) located at the Emmons Blaine Dairy Cattle Research Center (University of Wisconsin, Madison) were sampled for this study. Cows were fed a standard prefresh diet and given a pro-mineral mix (VitaPlus, Madison, WI). Incidence and severity (grade) of ketosis were recorded objectively for all animals during the first $10 \mathrm{~d}$ postpartum by testing urine with Ketostix Reagent Strips (Bayer Corp., Pittsburgh, PA), which measure acetoacetic acid, a ketone. Ketosis incidence was defined as $0=$ no ketosis, $1=$ yes, signs of ketosis. Ketosis grade was defined as follows: $1=$ mild ketosis with no treatment $(5 \mathrm{mg} / \mathrm{dL}$ acetoacetic acid), $2=$ mild ketosis with treatment $(15 \mathrm{mg} / \mathrm{dL}$ acetoacetic acid), $3=$ moderate ketosis with treatment $(40 \mathrm{mg} / \mathrm{dL}$ acetoacetic acid), and $4=$ severe ketosis with treatment $(>80 \mathrm{mg} / \mathrm{dL}$ acetoacetic acid). If trace ketones were detected in the urine, cows received 8 ounces $(\sim 237 \mathrm{~mL})$ of propylene glycol, and if cows had moderate to severe ketosis incidence they received 250 to $500 \mathrm{~mL}$ of $50 \%$ dextrose solution as treatments. Milk fever incidence was defined subjectively for all animals on d 1 of lactation as follows: $0=$ no signs of milk fever, $1=$ yes, signs of milk fever (i.e., subnormal body temperature, cold extremities, dry nose, ataxia, and recumbence). Blood samples were collected from coccygeal vessels on d 1 of lactation into commercial blood collection tubes (Vacuette, $9 \mathrm{~mL}$, Greiner Bio One, Monroe, NC) with and without anticoagulant (lithium heparin). Samples were then centrifuged at $3,000 \times g$ for $30 \mathrm{~min}$ at $4^{\circ} \mathrm{C}$ to harvest serum and plasma. Serum tubes were allowed to clot for $30 \mathrm{~min}$ before centrifugation. Serum and plasma were subsequently stored at $-80^{\circ} \mathrm{C}$ until analysis.

Serum concentrations of 5 -HT were analyzed by an ELISA (Serotonin EIA kit, \#ADI-900-175, Enzo Life Sciences, Farmingdale, NY) according to the manufacturer's instructions. The intra- and interassay coefficients of variation $(\mathbf{C V})$ were 8.5 and $9.2 \%$, respectively. A quantitative colorimetric calcium assay kit (\#700550, Cayman Chemical Company, Ann Arbor, MI) was used to determine serum concentrations of free ionized calcium. The intra- and interassay CV for the calcium assays were 8.2 and $9.4 \%$, respectively.
Plasma concentrations of PTHrP were measured by an immunoradiometric assay (Active PTHrP IRMA, \#DSL8100, Beckman Coulter, Brea, CA) according to the manufacturer's instructions. Plasma samples were analyzed within one assay. The intraassay CV for PTHrP was $0.01 \%$. Glucose concentrations were measured in plasma using a glucose oxidase-peroxidase assay that is specific for glucose (Karkalas, 1985). Serum was diluted 1:20 to detect glucose concentrations within the constraints of the assay. The detection limits for the glucose assay were $0.6 \mathrm{mg} / \mathrm{dL}$ and the interand intraassay CV were $2 \%$. Data were analyzed using Prism (version 6.0b, GraphPad Software, San Diego, CA). Normality and outlier tests were performed using Shapiro-Wilk normality test and Grubbs' test (extreme studentized deviate, ESD, method), respectively. Nonparametric Spearman rank correlations were performed to study the statistical dependency between the variables. Serum and plasma variables as well as milk fever data were obtained on d 1 of lactation. For ketosis grade, the most severe ketone body test (according to the Ketostix test) that the animal exhibited over the $10 \mathrm{~d}$ tested postparturition was used for each cow for analysis. For all analyses, differences between means were considered significant at $P \leq 0.05$.

Serum ionized calcium concentrations indicated that $27.5 \%$ of the cows in this study had subclinical hypocalcemia (calcium between 2 and $1.4 \mathrm{mmol} / \mathrm{L}$ ) and $10 \%$ had clinical hypocalcemia (calcium $<1.4 \mathrm{mmol} / \mathrm{L}$ ) on d 1 of lactation (DeGaris and Lean, 2008). Urine ketone bodies indicated that $50 \%$ of the cows experienced some grade of ketosis during the first $10 \mathrm{~d}$ postpartum. Serum 5-HT concentration on d 1 of lactation was negatively correlated with milk fever incidence $(\mathrm{r}=-0.33$, $P=0.039$, Figure 1A) on d 1 of lactation. Serum 5-HT concentration was positively correlated with ionized calcium concentrations $(\mathrm{r}=0.51, P=0.0008)$ and with plasma PTHrP concentrations $(\mathrm{r}=0.37, P=0.034)$ on d 1 of lactation (Figure 1B, C). Additionally, serum ionized calcium concentration was negatively correlated with milk fever incidence on $\mathrm{d} 1$ of lactation $(\mathrm{r}=-0.39$, $P=0.014$; Figure 1D). Serum 5-HT on d 1 of lactation was negatively correlated with the animal's most severe ketosis grade during the first $10 \mathrm{~d}$ postpartum $(\mathrm{r}=-0.69, P=0.0007$, Figure $2 \mathrm{~A})$, but was not correlated with ketosis incidence $(P>0.05)$. Additionally, serum glucose concentrations on d 1 were negatively correlated with the animal's most severe ketosis grade during the first $10 \mathrm{~d}$ postpartum $(\mathrm{r}=-0.46, P=0.043$, Figure $2 \mathrm{~B})$, but not with ketosis incidence $(P>0.05)$. Serum 5 -HT on d 1 of lactation was not correlated with serum glucose on the same day $(P>0.05)$. We have previously demonstrated that 5 -HT plays a role in the regulation of calcium and glucose homeostasis 

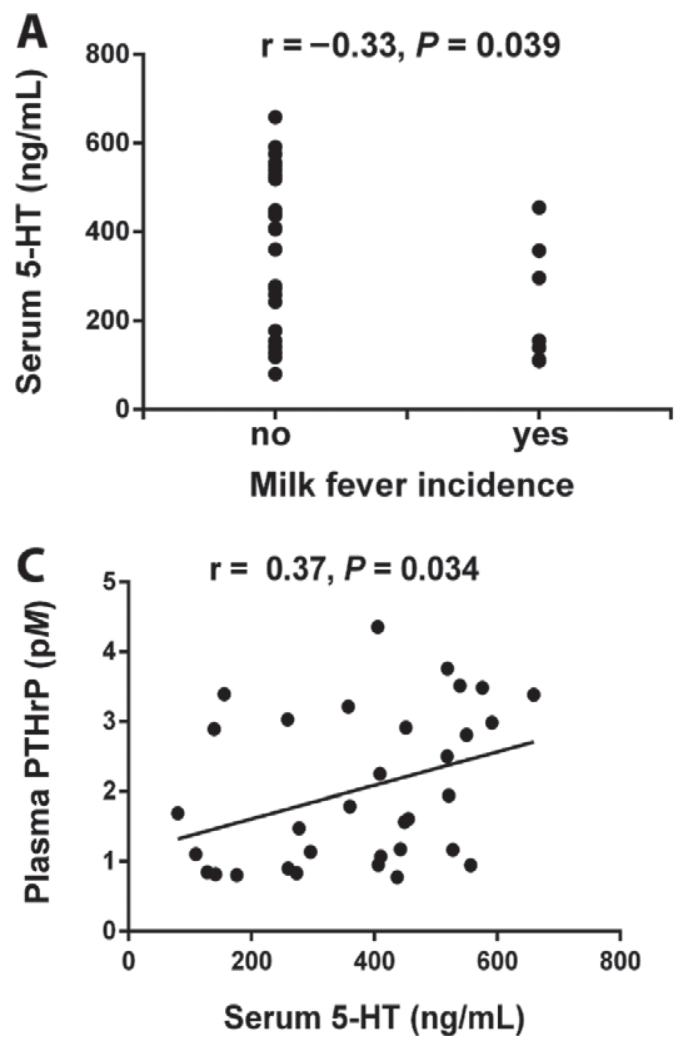
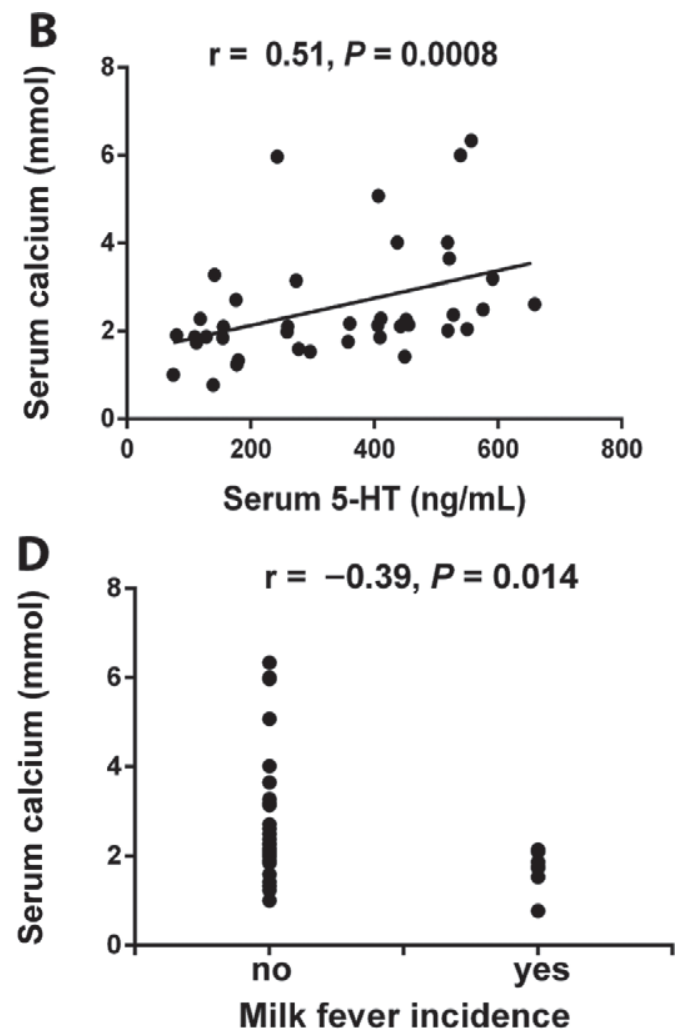

Figure 1. Spearman correlations between serum circulating serotonin (5-HT) concentrations on d 1 of lactation with (A) milk fever incidence (on d 1 of lactation), (B) serum ionized calcium (on d 1 of lactation), and (C) plasma parathyroid hormone-related protein (PTHrP, on d 1 of lactation) in Holstein cattle $(\mathrm{n}=42)$. Correlation between serum calcium and milk fever incidence on $\mathrm{d} 1$ of lactation is shown in (D). Milk fever incidence (yes/no) was determined subjectively (i.e., subnormal body temperature, cold extremities, dry nose, ataxia, and recumbence).

during the transition period in rodents (Laporta et al., 2013a,b). The findings reported herein are the first to depict the presence of relationships between circulating 5-HT with circulating PTHrP and calcium, and milk fever incidence and ketosis grade during the early periparturient period in multiparous Holstein cattle.

During lactation, extra demand for calcium by the mammary gland for milk production exerts stress on maternal calcium homeostasis, resulting in increased calcium absorption by the gastrointestinal tract, increased calcium retention by the kidneys, and a significant increase in bone loss (Wysolmerski, 2013). Synthesis of PTHrP by the mammary gland during lactation has been demonstrated to be critical for calcium mobilization from bone, which is necessary to support milk synthesis (Ardeshirpour et al., 2010; Carneiro et al., 2010; Wysolmerski, 2010; Horwitz et al., 2011). Previously, it has been demonstrated that mammary-specific deletion of PTHrP results in decreased concentrations of bone turnover markers and that 5-HT appears to be important for the stimulation of $\mathrm{PTHrP}$ production in the mammary gland (VanHouten et al., 2003; Hernandez et al., 2012). Our laboratory demonstrated that enhanced circulating PTHrP concentrations and bone mobilization of calcium were achieved by increasing 5-HT concentrations during the transition from pregnancy to lactation by feeding transition-phase rats supplemental 5-hydroxy-L-tryptophan, a direct precursor for 5-HT synthesis (Laporta et al., 2013b). Hernandez et al. (2012) demonstrated that 5-HT regulates induction of PTHrP in primary bovine mammary epithelial cells, and that lactating mice deficient in the rate-limiting enzyme in non-neuronal 5-HT synthesis (tryptophan hydroxylase 1) have reduced mammary and circulating PTHrP concentrations. Moreover, several studies have shown that 5 -HT is important for regulating bone mass in rodent and human models (Yadav et al., 2008; Mödder et al., 2010). The positive correlation between circulating 5-HT and circulating PTHrP and calcium observed in this study supports the potential role of 5 -HT as a mediator of calcium mobilization from bone through the induction of PTHrP on d 1 of lactation in dairy cattle.

In addition to the physiological role 5-HT may have in the regulation of calcium homeostasis during the transition from pregnancy to lactation, we observed that 

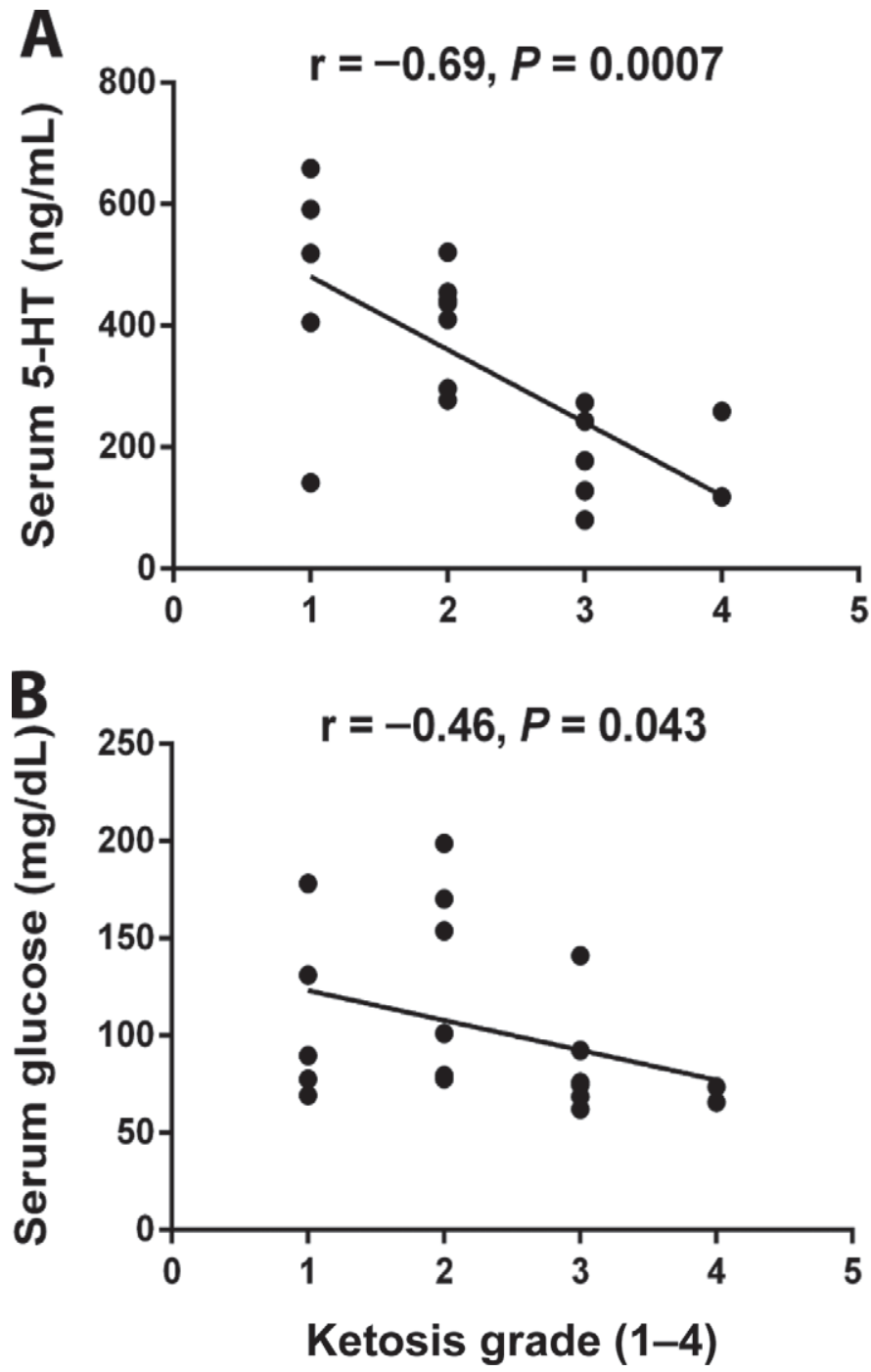

Figure 2. Spearman correlations between (A) serum circulating serotonin (5-HT) concentrations on d 1 of lactation and cow's most severe ketosis grade during the first $10 \mathrm{~d}$ postpartum, and (B) serum circulating glucose on $\mathrm{d} 1$ of lactation and cow's most severe ketosis grade during the first $10 \mathrm{~d}$ postpartum in Holstein cattle $(\mathrm{n}=42)$. Ketosis incidence was defined as $0=$ no ketosis, $1=$ yes, signs of ketosis (during the first $10 \mathrm{~d}$ postpartum), and ketosis grade was defined as follows: $1=$ mild ketosis with no treatment $(5 \mathrm{mg} / \mathrm{dL}), 2=$ mild ketosis with treatment $(15 \mathrm{mg} / \mathrm{dL}), 3=$ moderate ketosis levels with treatment $(40 \mathrm{mg} / \mathrm{dL})$ and $4=$ severe ketosis levels with treatment (>80 mg/dL) from urine using Ketostix Reagent Strips (Bayer Corp., Pittsburgh, PA).

cows with lower circulating concentrations of $5-\mathrm{HT}$ on d 1 of lactation correlated with the most severe grade of ketosis recorded during the first $10 \mathrm{~d}$ postpartum. Previous studies have indicated that 5 -HT is a regulator of glucose metabolism (Watanabe et al., 2011). We previously determined that increased circulating 5-HT concentrations in rats transitioning from pregnancy to lactation had increased liver mRNA expression of pyruvate carboxylase, a key control point in the regula- tion of glucogenic precursors entering the gluconeogenic pathway (Laporta et al., 2013a). Maintenance of efficient gluconeogenesis is critical for high-producing dairy cattle to prevent alterations in lipid metabolism that can lead to ketosis (Aschenbach et al., 2010). We did not see an association between 5-HT and glucose on d 1 of lactation, similar to the results of our study in rats, in which feeding 5-hydroxy-L-tryptophan did not affect circulating glucose concentrations despite having profound effects on gene expression of gluconeogenic and glycolytic enzymes in the liver (Laporta et al., 2013a). It is possible that 5-HT may be important at the transcriptional level in the liver and mammary gland in regulating glucose homeostasis, but the effects are not recognized at the circulating level.

In summary, this experiment provides preliminary evidence that 5-HT may be involved in regulation of calcium and glucose homeostasis in dairy cattle, which supports previous experiments performed in rodents, humans, and various in vitro experiments. It is important to note that these correlations only show the degree of relationship between the variables analyzed; more extensive studies are needed to explore the possibility of using 5-HT as a predictor of metabolic diseases in early lactation and the molecular mechanisms underlying these responses in dairy cattle. We are currently performing studies using genetically modified mouse models to delineate the molecular signaling mechanism(s) through which 5-HT induces PTHrP-mediated mobilization of calcium from bone during lactation and how 5-HT may regulate glucose metabolism during this time. A greater understanding of this physiological axis could help describe the underlying mechanisms associated with several periparturient metabolic disorders, including milk fever and ketosis, in dairy cows.

\section{REFERENCES}

Ardeshirpour, L., S. Brian, P. Dann, J. VanHouten, and J. Wysolmerski. 2010. Increased PTHrP and decreased estrogens alter bone turnover but do not reproduce the full effects of lactation on the skeleton. Endocrinology 151:5591-5601.

Aschenbach, J. R., N. B. Kristensen, S. S. Donkin, H. M. Hammon, and G. B. Penner. 2010. Gluconeogenesis in dairy cows: The secret of making sweet milk from sour dough. IUBMB Life 62:869-877.

Carneiro, R. M., L. Prebehalla, M. B. Tedesco, S. M. Sereika, M. Hugo, B. W. Hollis, C. M. Gundberg, A. F. Stewart, and M. J. Horwitz. 2010. Lactation and bone turnover: A conundrum of marked bone loss in the settling of coupled bone turnover. J. Clin. Endocrinol. Metab. 95:1767-1776.

Collier, R. J., L. L. Hernandez, and N. D. Horseman. 2012. Serotonin as a homeostatic regulator of lactation. Domest. Anim. Endocrinol. 43:161-170.

DeGaris, P. J., and I. J. Lean. 2008. Milk fever in dairy cows: A review of pathophysiology and control principles. Vet. J. 176:58-69.

Erb, H. N., R. D. Smith, P. A. Oltenacu, C. L. Guard, R. B. Hillman, P. A. Powers, M. C. Smith, and M. E. White. 1985. Path model of reproductive disorders and performance, milk fever, mastitis, milk yield, and culling in Holstein cows. J. Dairy Sci. 68:3337-3349. 
Grummer, R. R. 1995. Impact of changes in organic nutrient metabolism on feeding the transition dairy cow. J. Anim. Sci. 73:28202833.

Hernandez, L. L., K. A. Gregerson, and H. D. Horseman. 2012. Mammary gland serotonin regulates parathyroid hormone-related protein and other bone-related signals. Am. J. Physiol. Endocrinol. Metab. 302:E1009-1015.

Horwitz, M. J., M. B. Tedesco, S. M. Sereika, L. Prebehala, C. M. Gundberg, B. W. Hollis, A. Bisello, A. Garcia-Ocana, R. M. Carneiro, and A. F. Stewart. 2011. A 7-day continuous infusion of PTH or PTHrP suppresses bone formation and uncouples bone turnover. J. Bone Miner. Res. 26:2287-2297.

Karkalas, J. 1985. An improved enzymatic method for determination of native and modified starch. J. Sci. Food Agric. 36:1019-1027.

Kovacs, C. S. 2011. Calcium and bone metabolism disorders during pregnancy and lactation. Endocrinol. Metab. Clin. North Am. 40:795-826.

Laporta, J., T. L. Peters, K. E. Merriman, C. M. Vezina, and L. L. Hernandez. 2013a. Serotonin (5-HT) affects expression of liver metabolic enzymes and mammary gland glucose transporters during the transition from pregnancy to lactation. PLoS ONE 8:e57847 http://dx.doi.org/10.1371/journal.pone.0057847.

Laporta, J., T. L. Peters, S. R. Weaver, K. E. Merriman, and L. L. Hernandez. 2013b. Feeding 5-hydroxy-L-tryptophan during the transition from pregnancy to lactation increases calcium mobiliza- tion from bone in rats. Domest. Anim. Endocrinol. 44:176-184. http://dx.doi.org/10.1016/j.domaniend.2013.01.005.

Mödder, U. I., S. J. Achenbach, S. Amin, B. L. Riggs, L. J. I. I. I. Melton, and S. Khosla. 2010. Relation of serum serotonin leves to bone density and structural parameters in women. J. Bone Miner. Res. 25:415-422.

VanHouten, J. N., P. Dann, A. F. Stewart, C. J. Watson, M. Pollak, A. C. Karaplis, and J. J. Wysolmerski. 2003. Mammary-specific deletion of parathyroid hormone-related protein preserves bone mass during lactation. J. Clin. Invest. 112:1429-1436.

Watanabe, H., M. T. Rose, and H. Aso. 2011. Role of peripheral serotonin in glucose and lipid metabolism. Curr. Opin. Lipidol. 22:186-191.

Wysolmerski, J. J. 2010. Interactions between breast, bone, and brain regulate mineral and skeletal metabolism during lactation. Ann. N. Y. Acad. Sci. 1192:161-169.

Wysolmerski, J. J. 2013. Osteocytes remove and replace perilacunar mineral during reproductive cycles. Bone 54:230-236. http:/ dx.doi.org/10.1016/j.bone.2013.01.025.

Yadav, V. K., J.-H. Ryu, N. Suda, K. F. Tanaka, J. A. Gingrich, G. Schutz, F. H. Glorieux, C. Y. Chiang, J. D. Zajac, K. L. Insogna, J. J. Mann, R. Hen, P. Ducy, and G. Karsenty. 2008. Lrp5 controls bone formation by inhibiting serotonin synthesis in the duodenum. Cell 135:825-837. 